\title{
Escolha das Energias de Soldagem para Aplicação na Técnica da Dupla Camada na Soldagem do Aço ASTM 131 Grau AH 36
}

\author{
Leandro Macedo Cozza ${ }^{1}$ (D), Jorge Luis Braz Medeiros ${ }^{1}$, Luciano Volcanoglo Biehl' ${ }^{1}$, José de Souza ${ }^{2}$, Demostenes Ferreira Filho ${ }^{3}$ (D) \\ ${ }^{1}$ Universidade Federal do Rio Grande - FURG, Escola de Engenharia, Programa de Pós-Graduação em Engenharia Mecânica - PPMec, Rio Grande, RS, Brasil. \\ 2 Escola Técnica Liberato Salzano Vieira da Cunha, Novo Hamburgo, RS, Brasil. \\ ${ }^{3}$ Universidade Federal de Goiás - UFG, Escola de Engenharia Elétrica, Mecânica e de Computação, Goiânia, GO, Brasil.
}

Como citar: Cozza LM, Medeiros JLB, BiehI LV, Souza J, Ferreira Filho D. Escolha das Energias de Soldagem para Aplicação na Técnica da Dupla Camada na Soldagem do Aço ASTM 131 Grau AH 36. Soldagem \& Inspeção. 2019; 24:e2405. https://doi.org/10.1590/01049224/S124.05

\begin{abstract}
Resumo: Durante o processo de soldagem o aço microligado ASTM A131 Grau AH36 pode apresentar defeitos oriundos dos ciclos térmicos (distorções) que demandarão procedimentos onerosos como o tratamento térmico póssoldagem. Somando-se a isto, este aço não é indicado a sofrer normalização, normalização seguida por revenimento, ou por têmpera e revenimento. Neste caso, a técnica da dupla camada, que se baseia na deposição controlada dos passes da primeira e segunda camada através da escolha apropriada da relação de energias de soldagem, surge como alternativa. Diante disto, este trabalho teve por objetivo encontrar a relação de energia de soldagem que satisfizesse os critérios de microdureza e macrografia. Para isto foram realizadas soldagens preliminares para cada energia e após isto a comprovação com a soldagem de dupla camada em chapa plana. Os resultados indicaram que as relações de

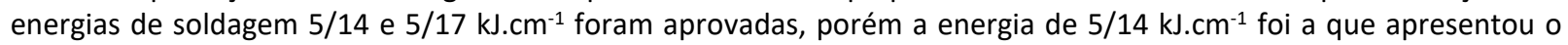
maior afastamento no critério baseado na microdureza. A soldagem com dupla camada comprovou que a relação de energia encontrada foi adequada apresentando microdurezas com valores inferiores ao limite da zona endurecida (300 HV0,1) demonstrando a possibilidade de revenimento ocasionado pela sobreposição dos passes.
\end{abstract}

Palavras-chave: Soldagem; Dupla camada; ASTM 131 grau AH36.

\section{Choice of Welding Energies for Application in Double Welding Technique in Welding of Steel ASTM 131 Grade AH 36}

\begin{abstract}
During the welding process ASTM A131 Grade AH36 microalloyed steel may exhibit thermal cycling defects (distortions) that will require costly procedures such as post-weld heat treatment. In addition, this steel is not indicated to undergo normalization, normalization followed by tempering, or quenching and tempering. In this case, the double layer technique, which is based on the controlled deposition of the first and second layer passes through the appropriate choice of the welding energies ratio, appears as an alternative. In view of this, this work had as objective to find the relation of welding energy that satisfies the criteria of microhardness and macrography. For this purpose, preliminary welds were carried out for each energy and after that the verification with the welding of double layer in flat plate. The results indicated that the welding energy ratios 5/14 and 5/17 $\mathrm{kJ}_{\mathrm{cm}} \mathrm{cm}^{-1}$ were approved, but the energy of $5 / 14 \mathrm{~kJ}_{\mathrm{cm}} \mathrm{cm}^{-1}$ was the one that presented the greatest distance in the criterion based on microhardness. The double layer welding showed that the found energy ratio was adequate, presenting microhardness values lower than the limit for the hardened zone $(300 \mathrm{HV} 0,1)$, demonstrating the possibility of tempering by the overlapping of passes.
\end{abstract}

Key-words: Welding; Double layer; ASTM 131 grade AH36.

\section{Introdução}

Atualmente empregado na indústria mecânica como estruturas em cascos de plataformas de petróleo, o aço ASTM A131 AH36, processado por TMCP (thermomechanical controlled processing), possui alta resistência mecânica resultante de três mecanismos de endurecimento: refinos de grão austenítico e ferrítico, dispersão de carbonitretos e carbonetos, e aumento de densidade de discordâncias. Esses três mecanismos têm permitido aos fabricantes reduzir o teor de carbono dos aços (<0,10\%) e melhorar sua soldabilidade [1]. 
Dependendo da composição e das condições de processamento, os aços TMCP têm microestrutura formada pela transformação da austenita em ferrita/perlita, ferrita/bainita, ferrita/martensita ou ainda uma mistura de vários constituintes. Um exemplo, neste caso, pode ser a aplicação do resfriamento acelerado ao fim do processo com objetivo de promover a formação de ferrita acicular ao invés de ferrita poligonal contribuindo para uma combinação favorável de alta resistência mecânica porém sem apresentar decréscimo na tenacidade ao impacto [1,2].

Este mesmo aço pode apresentar, em juntas soldadas, defeitos oriundos dos ciclos térmicos (distorções), processos de soldagem aplicada e/ou das habilidades operacionais (principalmente em processos manuais como eletrodo revestido (SMAW), por exemplo). No controle e eliminação destes defeitos normalmente se utiliza do procedimento de reparo da junta soldada. Este é um processo que requer uma série de providências e adequações para que a zona afetada pelo calor (ZAC) tenha as características mecânicas e metalúrgicas similares à junta antes do reparo. Para estes objetivos são utilizados alguns procedimentos, dentre os quais a aplicação de tratamento térmico pós-soldagem (TTPS) que visa diminuir a microdureza, reduzir as tensões residuais e garantir uma boa tenacidade fratura na região recuperada. Porém o TTPS muitas vezes pode ser uma alternativa onerosa e até mesmo inviável por comprometer questões relativas a tempo, custo e processo, pois nem sempre podem ser realizados devido as suas questões operacionais, além das dimensões das estruturas.

Somando-se a inviabilidade do tratamento térmico, este aço não é indicado a sofrer normalização, normalização seguida por revenimento, ou por têmpera e revenimento. Estes processos podem deteriorar as propriedades de tração e/ou tenacidade. Se o tratamento térmico para alívio de tensões (TTAT) é requerido pelas normas de fabricação de equipamentos, ele deve ser realizado com o único propósito de relaxamento de tensões residuais e não para modificar as propriedades mecânicas como frequentemente se faz com os aços convencionais devido às temperaturas aplicadas [1].

Neste caso, uma alternativa que surge com potencial para contornar estas questões é a utilização de técnicas especiais de soldagem sem tratamento térmico posterior, uma vez que não foi encontrado estudos sobre a aplicação das mesmas neste tipo de aço. Dentre elas se destaca a técnica da dupla camada que se baseia na deposição controlada dos passes da segunda e primeira camadas e da relação de energia de soldagem de tal forma que ocorra então o revenimento e o refino microestrutural na zona afetada pelo calor.

A técnica de dupla camada consiste em promover uma adequada sobreposição dos ciclos térmicos de tal forma que a segunda camada promova o refino e o revenimento da zona afetada pelo calor - grão grosseiro (ZAC-GG) da primeira camada, conforme mostra a Figura 1 [3].

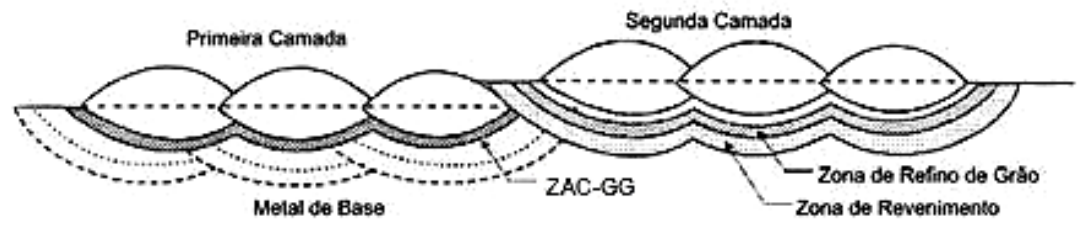

Figura 1. Esquema das sub-regiões da ZAC em uma soldagem multipasses.

A técnica da dupla camada tem sido pesquisada com intuito de evitar este tratamento térmico e garantir boas propriedades mecânicas da peça soldada. Farias e Aguiar [4], no estudo do aço ABNT 4140, mostraram que o grau de refino da ZAC-GG foi satisfatório. Os melhores resultados foram obtidos com baixos aportes de energia na primeira camada, onde as relações de energia de $1 / 1$ e 1/2 entre as camadas foram utilizadas. Os autores observaram que o uso de uma elevada energia na deposição da primeira camada promoveria um maior crescimento de grão, o que por sua vez, implicaria em dificuldade de refino pela segunda camada prejudicando a tenacidade da mesma.

Lant et al. [5] recomendam o controle de alguns parâmetros para que a técnica seja bem sucedida, sendo eles, a altura média e penetração referentes a primeira camada e a profundidade refinada pela segunda camada. Melhores resultados são alcançados com mínimo aporte de calor na primeira camada e percentual de sobreposição de 30 a $50 \%$. Com $50 \%$ de sobreposição pode-se obter refino de até $80 \%$ na ZAC-GG.

Alguns autores buscaram avaliar a influência da técnica da dupla camada nas propriedades dos componentes soldados. De acordo com resultados, controlando adequadamente os parâmetros de soldagem, a própria energia do segundo passe é capaz de revenir e refinar a ZAC-GG do primeiro. Sabe-se desses estudos que baixos aportes de energia na primeira camada mostram-se, em geral, satisfatórios, uma vez que uma elevada energia de soldagem na primeira camada poderia acarretar crescimento de grão ocasionando em dificuldade de refino pela segunda camada $[6,7]$.

A ferramenta mais comumente utilizada para selecionar as relações de energia utilizadas na soldagem da dupla camada é o critério de microdureza, que consiste em realizar a soldagem de cordões simples e, em seguida, realizar a medição da geometria dos cordões (reforço e penetração) e uma varredura de microdureza (partindo da linha de fusão e abrangendo toda a região da ZAC bem como parte do metal base). O critério de macrografia é semelhante ao critério de dureza. Enquanto o primeiro critério baseia-se na dureza para delimitar as regiões da ZAC (zona endurecida e zona não endurecida), o critério de 
macrografia baseia-se na macrografia para delimitar a região da ZAC com granulação grosseira (ZAC-GG) e a região com granulação fina (ZAC-GF) [8].

A técnica da dupla camada se mostrou eficaz na melhora das propriedades da microestrutura da ZAC-GG e refino de grão na soldagem de revestimento da liga de Níquel no aço ASTM A387 Grau 11 pelo processo de soldagem MIG/MAG. Houve também redução nas medidas de microdureza e ficou comprovado que quanto maior a energia da primeira camada maior a tendência de reprovação nos diagramas de decisão dos critérios de microdureza e microestrutura, pois maior será a zona dura ou a ZAC-GG [9].

Cruz [10] encontrou (através dos diagramas de decisão) a melhor relação de energia em 6/10 kJ.cm ${ }^{-1}$. Embora, possa

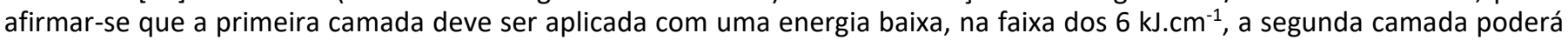
ser realizada com uma faixa maior $\left(6,10\right.$ ou $\left.14 \mathrm{~kJ} . \mathrm{cm}^{-1}\right)$. Este fato possibilita a aplicação da dupla camada em campo, apesar da dificuldade de se manter a energia de soldagem controlada no processo de soldagem manual.

Desta forma, o presente trabalho tem como objetivo encontrar a relação de energia de soldagem que satisfaça os critérios de microdureza e macrografia aliados aos diagramas de decisões de tal forma que ocorra então o revenimento e o refino microestrutural na zona afetada pelo calor no aço ASTM A131 Grau AH36 para que o TTPS possa ser evitado na tentativa de reduzir a microdureza e distorções relacionadas as tensões residuais.

\section{Materiais e Métodos}

\subsection{Materiais}

\subsubsection{Metal de base e de adição}

O metal de base utilizado neste trabalho foi o aço ASTM A131 Grau AH36, fornecido sob a forma de chapa laminada de $750 \times 1300 \times 12,5(\mathrm{~mm})$.

A fim de obter o controle das variáveis de soldagem, o que pode ser considerado crucial nesta pesquisa, optou-se por escolher o processo de soldagem GMAW semiautomático com metal de adição AWS ER70S-6 de 1,2 mm de diâmetro com $100 \%$ de $\mathrm{CO}_{2}$ como gás de proteção.

\subsection{Metodologia}

\subsubsection{Caracterização do metal de base}

As amostras foram cortadas e submetidas à preparação metalográfica para caracterização microestrutural através do microscópio ótico com sistema de análise de imagens e medição de composição química com espectrômetro ótico. Também foram realizados ensaios de microdureza com um microdurômetro Vickers.

\subsubsection{Soldagem preliminar}

Nesta etapa foi realizado um primeiro cordão de soldagem com deposição sobre chapa de dimensões 150 x 80 x 12,5 ( $\mathrm{mm}$ ) na posição plana.

O objetivo da aplicação desta técnica foi encontrar uma relação entre as energias da primeira e segunda camada. Neste quesito foram testados quatro níveis de energias de soldagem com a variação da energia controlada pela velocidade de soldagem.

Os corpos de prova foram soldados com distância bico de contato-peça (DBCP) de $12 \mathrm{~mm}$ e vazão de gás de $16 \mathrm{I}$. min ${ }^{-1}$. A fim de parametrizar os valores de corrente e tensão foi necessário regular a fonte de soldagem com velocidade de alimentação de $4 \mathrm{~m} \cdot \mathrm{min}^{-1}$ e tensão de operação em $25 \mathrm{~V}$. A corrente e a tensão de soldagem foram monitorados durante os testes com um sistema de aquisição de dados operando com uma frequência de $2 \mathrm{kHz}$. A Tabela 1 apresenta os valores de tensão e corrente encontrados, as velocidades de soldagem reguladas e as energias de soldagem calculadas.

Tabela 1. Parâmetros de soldagem.

\begin{tabular}{ccccc}
\hline Corpo de Prova & (V) & (A) & $\begin{array}{c}\text { Velocidade de Soldagem } \\
\text { (cm.min } \mathbf{- 1})\end{array}$ & (kJ.cm $^{-1}$ ) \\
1 & 24,3 & 125 & 39,6 & 5 \\
2 & 25,0 & 124 & 21,6 & 9 \\
3 & 24,4 & 128 & 13,2 & 14 \\
4 & 24,2 & 126 & 10,7 & 17 \\
\hline
\end{tabular}


Após a soldagem das placas de teste confeccionaram-se as amostras para realizar as medições de microdureza conforme apresentado na Figura 2 (a). As medições de microdureza seguiram a mesma metodologia apresentada por Cruz [10] e Azevedo [11]. Os ensaios percorreram transversalmente as regiões da solda, desde a ZF até o metal de base (afastamento aproximado de $30^{\circ}$ para cada serie de impressões, sendo uma das direções normal ao plano superior da amostra) com uma distância de 0,2 mm para uma carga de $100 \mathrm{~g}$ aplicada durante 10 segundos conforme Figura 2 (b). Os valores de microdureza média foram empregados para avaliar os tamanhos das zonas endurecidas (ZE) e zonas não endurecidas (ZNE).

Nas três amostras retiradas da placa de teste também foram utilizadas para as medições da ZAC-GG, ZAC-GF, reforço (R) e penetração $(P)$ utilizando um microscópio ótico para cada energia de soldagem e posteriores medições com auxílio do aplicativo Image J.

\section{Cordão de solda}

a)

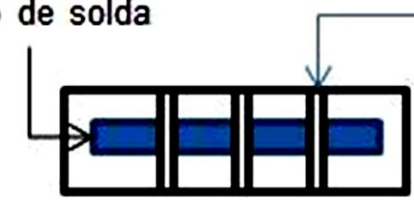

Amostras

b)

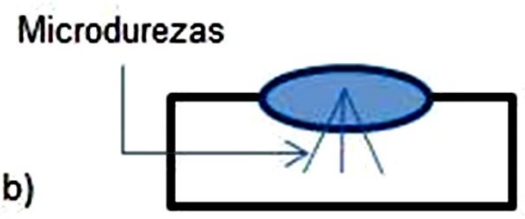

Figura 2. Retirada das amostras: a) Transversal ao corpo de prova; b) Detalhe das amostras com as linhas de direção para medição de microdureza.

\subsubsection{Critérios de análise para os diagramas de decisão}

Os perfis de microdurezas bem como os dos perfis oriundos das macrografias serviram de parâmetro para construção dos diagramas e foram submetidos aos critérios representados nas Equações 1 a 4.

\section{Critério do Perfil do Cordão baseado na Microdureza}

$\left(P Z N E_{2}\right)>\left(P Z E_{1}\right)$

$\left(R_{1}+P_{1}\right)>\left(P Z E_{2}\right)$

onde: $\mathrm{PZNE}_{2}$ representa a profundidade da zona não endurecida da segunda camada, $\mathrm{PZE}_{1}$ representa a profundidade da zona endurecida da $1^{\circ}$ camada, $R_{1}$ representa a altura do reforço da primeira camada e $P_{1}$ representa a medida da penetração da primeira camada.

\section{Critério do Perfil do Cordão baseado na Macrografia}

$\left(P Z A C-G F_{2}\right)>\left(P Z A C-G G_{1}\right)$

$\left(Z F_{1}\right)>\left(P Z A C-G G_{2}\right)$

onde: $\mathrm{ZF}_{1}$ representa o somatório do reforço e da penetração na primeira camada, PZAC-GF2 a profundidade da zona afetada pelo calor com granulação fina da segunda camada, $P Z A C-G_{1}$ profundidade da zona afetada pelo calor da granulação grosseira da primeira camada e PZAC-GG 2 representa a profundidade da zona afetada pelo calor da granulação grosseira da segunda camada.

\subsubsection{Soldagem com a dupla camada com deposição sobre chapas}

O ensaio da relação de energias consistiu em aplicar cordões (soldagem semiautomática) sobre chapa com a técnica da dupla camada, utilizando os parâmetros da Tabela 1 a fim de verificar se o nível de revenimento atingido pela dupla camada 
está de acordo com os valores pré-estabelecidos de microdureza conforme a relação de energias estabelecida na soldagem preliminar. Para isso foram então depositados sete passes na primeira camada e três passes na segunda com uma sobreposição aproximada de 50\% para ambas conforme definido por Lant et al. [5].

Após a soldagem, três amostras foram retiradas transversalmente da placa de teste soldada com duas camadas (Figura 2) para medição dos perfis de microdurezas. Os ensaios percorreram desde a linha de fusão da primeira camada (região correspondente aos $2^{\circ}, 4^{\circ}$ e $6^{\circ}$ passes, respectivamente) até o metal de base com distância entre pontos de $0,2 \mathrm{~mm}$ para uma carga de 100 g aplicada durante 10 segundos conforme metodologia aplicada por Cruz [10] e Azevedo [11] (Figura 3).

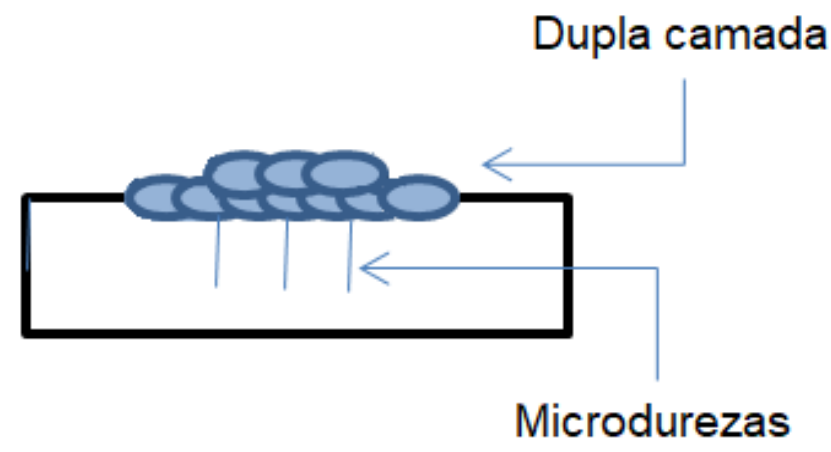

Figura 3. Detalhe da amostra da solda em dupla camada para medição dos perfis de microdureza.

\section{Resultados e Discussão}

\subsection{Caracterização do metal de base}

\subsubsection{Análise microestrutural}

A verificação microestrutural no metal de base $(\mathrm{MB})$ revelou a presença de estrutura bandeada indicando uma segregação preferencial da perlita ao longo do material, e que a microestrutura presente no MB é composta basicamente de ferrita e perlita em menor quantidade conforme verificado por Cruz [10] em seu trabalho sobre aços microligados. A Figura 4 mostra a presença de ferrita (grãos claros) e perlita (constituintes escuros). Ainda na mesma é possível verificar a estrutura de bandas características do processo TMCP típico desses tipos de aço.

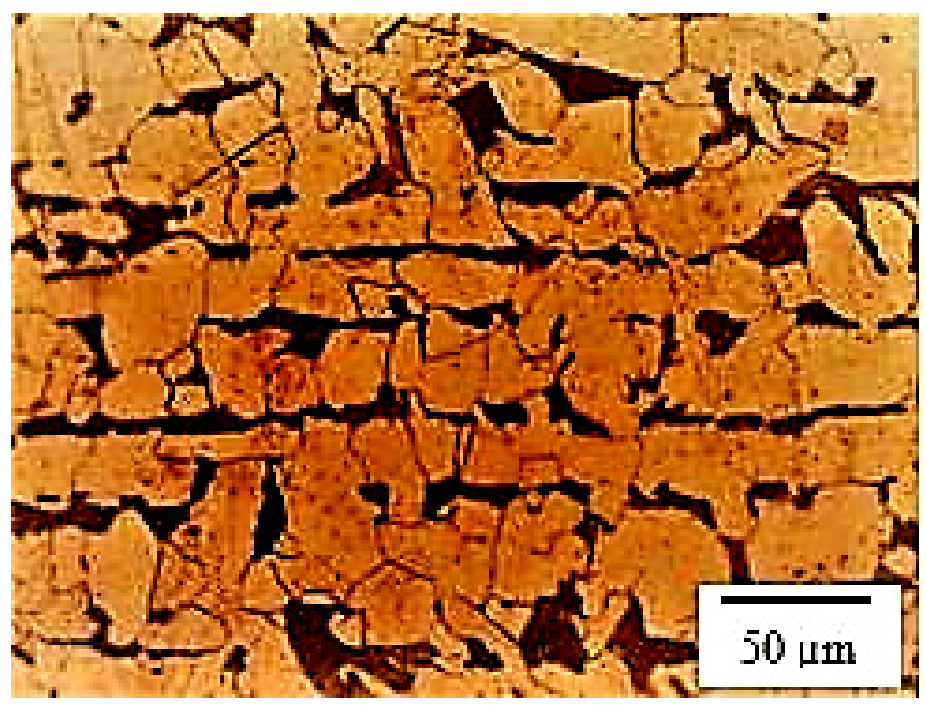

Figura 4. Micrografia da seção transversal do metal de base. 


\subsubsection{Análise química}

A Tabela 2 mostra a composição química do AH36 analisado nesta pesquisa.

Tabela 2. Composição química da amostra do aço ASTM A131 grau AH36.

\begin{tabular}{ccccccccccccc}
\hline (\%) & $\mathbf{( \% )}$ & $\mathbf{( \% )}$ & $\mathbf{( \% )}$ & $\mathbf{( \% )}$ & $\mathbf{( \% )}$ & $\mathbf{( \% )}$ & $\mathbf{( \% )}$ & $\mathbf{( \% )}$ & $\mathbf{( \% )}$ & $\mathbf{( \% )}$ & (\%) & (\%) \\
\hline, 09 & 1,44 & 0,30 & 0,01 & 0,01 & 0,04 & 0,01 & 0,01 & 0,01 & 0,03 & 0,01 & 0,01 & 0,01 \\
\hline
\end{tabular}

O aço identificado na Tabela 1 é caracterizado com aço de baixo carbono, porém em sua composição química apresenta elementos como o Manganês que contribuem para o aumento da temperabilidade. Ainda deve ser destacado que a presença dos elementos microligantes nióbio e vanádio em associação com o alumínio contribuem para a formação de carbonetos e nitretos precipitados, que além de "ancorarem" o tamanho de grão, contribuem para a presença pontual do aumento da resistência mecânica destes aços.

Quando os mesmos recebem aporte térmico inadequado pode existir degradação do tamanho de grão austenítico e das propriedades mecânicas, sendo por isto o controle do aporte térmico e das taxas de resfriamento fundamentais para o melhor desempenho destes aços quando da necessidade de soldagem.

\subsubsection{Medição de microdureza}

Na Tabela 3 é apresentada a faixa de valores de microdureza encontrados, média e o seu respectivo desvio padrão.

Tabela 3. Medições de microdureza do metal de base.

\begin{tabular}{ccc}
\hline (HV0,1) & (HV0,1) & (HV0,1) \\
$190-215$ & 200 & 8,47 \\
\hline
\end{tabular}

\subsection{Soldagem preliminar}

A Figura 5 apresentados os aspectos visuais dos cordões de solda conforme a energia de soldagem.

a)
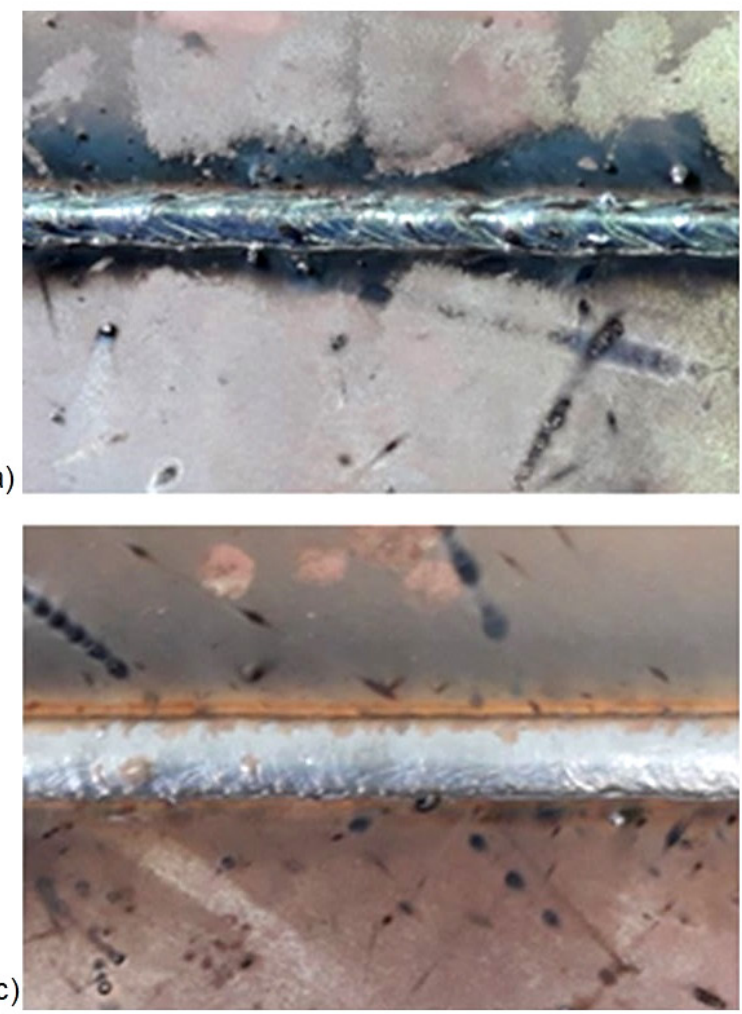
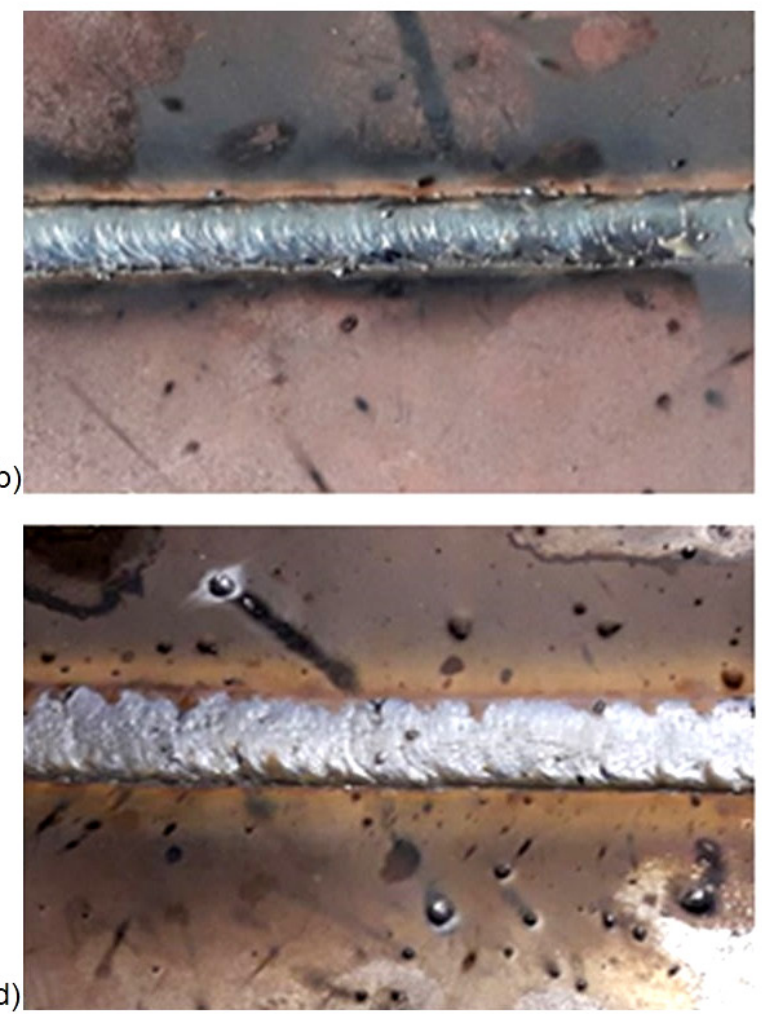

Figura 5. Aspecto visual dos cordões de solda de acordo com a energia de soldagem: a) $5 \mathrm{~kJ} . c m^{-1}$ b) $\left.9 \mathrm{~kJ} \mathrm{~cm}^{-1} \mathrm{c}\right) 14 \mathrm{~kJ} . \mathrm{cm}^{-1} \mathrm{e} \mathrm{d)} 17 \mathrm{~kJ} . \mathrm{cm}^{-1}$. 
Os cordões de solda apresentam acabamento satisfatório e sem descontinuidades aparentes para todas as energias de soldagem. Hu et al. [12] em seu estudo para aços microligados encontrou as melhores propriedades mecânicas para aportes similares de energia (neste caso 9 e $14 \mathrm{~kJ}_{\mathrm{cm}} \mathrm{cm}^{-1}$ ) identificando que, apesar de aumentar a produtividade, um aumento de energia pode não ser benéfico em termos de integralidade da junta soldada.

Uma vez que a tensão e corrente não sofreram variações significativas, o aumento na largura dos cordões pode ser atribuído à diminuição da velocidade de soldagem que está diretamente ligada à quantidade de energia cedida à peça. Velocidades mais baixas, além de elevar o custo da operação, podem causar alterações metalúrgicas na estrutura do material devido à concentração térmica e aumentam assim a dimensão do cordão o que é corroborado e destacado por Machado [13] em seu trabalho.

Para as medições das extensões das zonas endurecida e não endurecida, foi adotado um limite de 300 HV0,1 para o fim da ZE e começo da ZNE e 200 HV0,1 para o fim da ZNE, já que esta é a microdureza média do metal de base. Este critério também foi utilizado por Andrade [8] e Cavalcante et al. [9] em reparos de aços de baixa liga Cr-Mo. A varredura de microdureza permite delimitar a extensão de zona dura e da zona não endurecida da ZAC da seguinte forma: a ZE começa na linha de fusão, onde $x=0$, e se estende até a região em que os valores de microdureza caem para níveis menores que 300 HV0,1 e a ZNE vai do final da ZE até o primeiro ponto onde a microdureza é a mesma do metal de base $(200 \mathrm{HV0,1)}$.

A Figura 6 ilustra os perfis de microdureza encontrados para as energias 5, 9, 14 e $17 \mathrm{~kJ} . \mathrm{cm}^{-1}$

a)

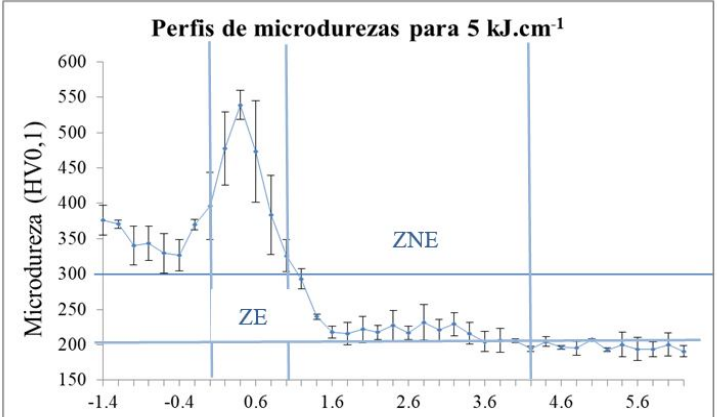

c)

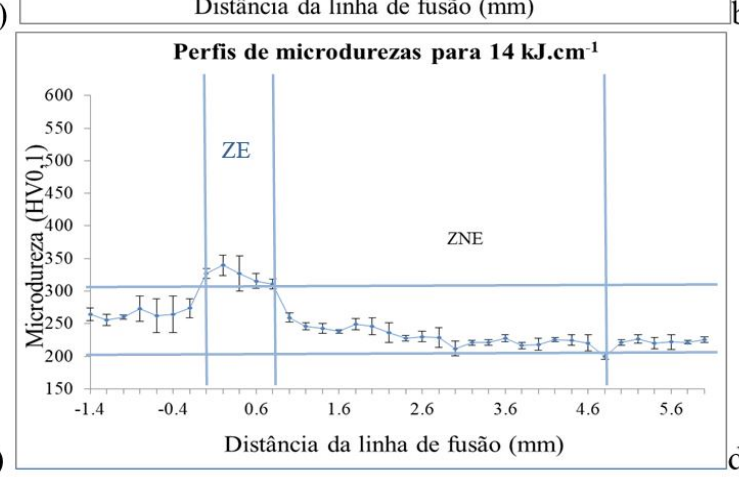

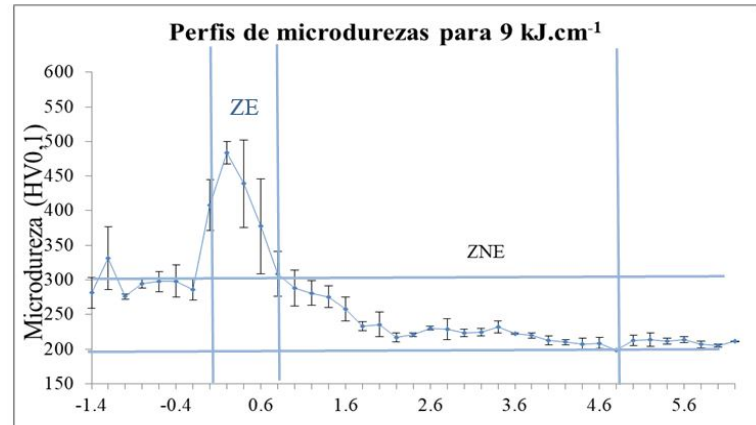

b)

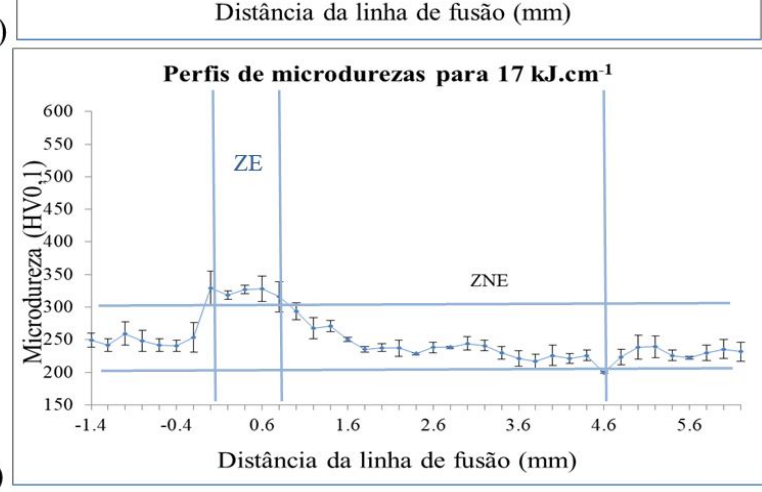

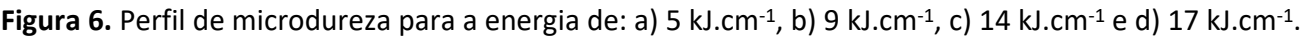

Para as quatro energias de soldagem utilizadas os menores valores de pico de microdureza ficaram em torno de 350 HV0,1 (Figuras 6 (c) e (d)) e os maiores valores de pico encontrados chegaram próximos de 500 HV0,1, como mostrado nas Figuras 6 (a) e (b). Pode-se observar também por meio destes diagramas que a microdureza tende a reduzir à medida que se afasta da linha de fusão, com picos de microdureza na zona com maior velocidade de resfriamento e uma diminuição desde a zona endurecida até o metal de base definindo a zona não endurecida já com menores taxas de resfriamento.

O pico de dureza diminui à medida que a energia de soldagem aumenta provavelmente em consequência de dois fatores: aumento da quantidade de austenita retida e de bainita. A primeira aumenta devido ao maior tempo de permanência em temperaturas elevadas proporcionado pelo uso de energias mais altas, o que faz com que haja uma maior dissolução do carbono e dos elementos de liga, baixando as temperaturas de martensita inicial e final. Já a quantidade de bainita aumenta com a diminuição da velocidade de resfriamento proporcionada pelo uso de energias mais elevadas [4,10].

A presença de valores de microdureza elevada como encontradas nos perfis de energias mais baixas podem estar associadas ao crescimento de grão da austenita nessa região (maior temperabilidade) associado a um resfriamento mais rápido (menor energia de soldagem).

As medidas das regiões da solda, das regiões endurecidas e não endurecidas são apresentadas na Tabela 4. Os perfis medidos das amostras em função da macrografia são apresentados na Tabela 5. 
Tabela 4. Medidas das zonas da solda em função da microdureza.

\begin{tabular}{|c|c|c|c|c|c|c|c|c|}
\hline \multirow[b]{3}{*}{ Energia $\left(\mathbf{k J} . \mathrm{cm}^{-1}\right)$} & \multicolumn{6}{|c|}{ Zonas do cordão de solda (mm) } & \multirow{2}{*}{\multicolumn{2}{|c|}{17}} \\
\hline & \multicolumn{2}{|r|}{5} & \multicolumn{2}{|c|}{9} & \multicolumn{2}{|c|}{14} & & \\
\hline & Média & Desvio Padrão & Média & Desvio Padrão & Média & $\begin{array}{l}\text { Desvio } \\
\text { Padrão }\end{array}$ & Média & $\begin{array}{l}\text { Desvio } \\
\text { Padrão }\end{array}$ \\
\hline Reforço & 4,3 & 0,7 & 6,8 & 1,3 & 6,5 & 1,3 & 5,6 & 0,6 \\
\hline Penetração & 3,0 & 0,5 & 2,9 & 0,7 & 4,2 & 0,8 & 4,0 & 0,3 \\
\hline ZE & 1,0 & 0,2 & 0,9 & 0,2 & 0,8 & 0,0 & 0,8 & 0,2 \\
\hline ZNE & 3,2 & 0,2 & 3,9 & 0,2 & 4,0 & 0,0 & 3,8 & 0,2 \\
\hline
\end{tabular}

Tabela 5. Medidas do perfil em função da macrografia.

\begin{tabular}{|c|c|c|c|c|c|c|c|c|}
\hline \multicolumn{9}{|c|}{ Zonas do Cordão de Solda (mm) } \\
\hline \multirow[b]{2}{*}{ Energia $\left(\mathrm{kJ} . \mathrm{cm}^{-1}\right)$} & \multicolumn{2}{|c|}{5} & \multicolumn{2}{|c|}{9} & \multicolumn{2}{|c|}{14} & \multicolumn{2}{|c|}{17} \\
\hline & Média & $\begin{array}{l}\text { Desvio } \\
\text { Padrão }\end{array}$ & Média & $\begin{array}{l}\text { Desvio } \\
\text { Padrão }\end{array}$ & Média & $\begin{array}{l}\text { Desvio } \\
\text { Padrão }\end{array}$ & Média & $\begin{array}{l}\text { Desvio } \\
\text { Padrão }\end{array}$ \\
\hline Reforço & 4,3 & 0,7 & 6,8 & 1,3 & 6,5 & 1,3 & 5,6 & 0,6 \\
\hline Penetração & 3,0 & 0,5 & 2,9 & 0,7 & 4,2 & 0,8 & 4,0 & 0,3 \\
\hline ZAC-GG & 1,4 & 0,1 & 1,4 & 0,4 & 2,0 & 0,4 & 3,0 & 0,0 \\
\hline ZAC-GF & 1,3 & 0,2 & 2,9 & 0,2 & 2,9 & 0,6 & 1,7 & 0,0 \\
\hline
\end{tabular}

Observou-se que a dimensão do reforço aumentou quando se variou a energia de $5 \mathrm{~kJ} . \mathrm{cm}^{-1}$ para $9 \mathrm{~kJ} . \mathrm{cm}^{-1}$, e para os demais aumentos do aporte térmico não se observou uma variação significativa na dimensão do reforço. Esse aumento no reforço pode ser atribuído à maior oferta de material de adição, uma vez que, à medida que diminuía a velocidade de soldagem, aumentava-se a quantidade de arame fundido por comprimento de solda, como apresentado na Tabela 1 [7]. Já os valores de penetração não obtiveram variação significativa para as energias de 5 e $9 \mathrm{~kJ} . \mathrm{cm}^{-1}$, porém observou-se um aumento da medida da penetração da energia de 9 para a de $14 \mathrm{~kJ} \cdot \mathrm{cm}^{-1}$, que provavelmente ocorreu devido ao aumento do aporte térmico utilizado. Um dos fatores para esse comportamento está diretamente relacionado com a dinâmica do fluxo de calor, onde que, à medida que se aumenta a quantidade de calor fornecida ao sistema conduz ao aumento do volume de metal fundido [7].

Para o tipo de material considerado, a ZE deve estar contida na ZAC-GG. A ZAC-GG aumenta com o aporte térmico porque a distribuição de temperaturas de pico (repartição térmica) se torna mais aberta (além dos tempos de permanência a alta temperatura aumentarem). Por outro lado, a ZE mostra uma tendência (pouco significativa) de diminuir devido à queda de dureza da ZAC-GG com o aporte térmico (menor velocidade de resfriamento).

Apesar de possuírem tendências parecidas, os critérios para a escolha da energia de soldagem possuem cada um sua particularidade o que justifica a inclusão de ambos na construção do diagrama de decisão. $O$ critério baseado na microdureza tem o objetivo de determinar as extensões das zonas endurecidas e não endurecidas ao longo da ZAC do material com base nos perfis de microdureza e pela geometria do cordão (reforço e penetração). O critério baseado na macrografia foi desenvolvido posteriormente com intuito de proporcionar uma análise mais confiável e completa na escolha das energias e difere do anterior pela abordagem, já que é baseado nas extensões das zonas microestruturais (ZAC-GG e ZAC-GF) [8].

A definição da relação entre as energias da primeira e da segunda camada, obedecendo aos critérios de perfil do cordão baseado na microdureza e do perfil do cordão baseado na macrografia (Equações 1 a 4), foi realizada com o auxilio dos diagramas de decisão apresentados na Figura 7. Os afastamentos positivos (valores maiores que zero) indicam que o critério foi satisfeito (desde que todos os pontos para um mesmo critério e relação de energias estejam localizadas nos afastamentos positivos). Foram construídos quatro diagramas resultando em dezesseis combinações de relações de energia de soldagem. 

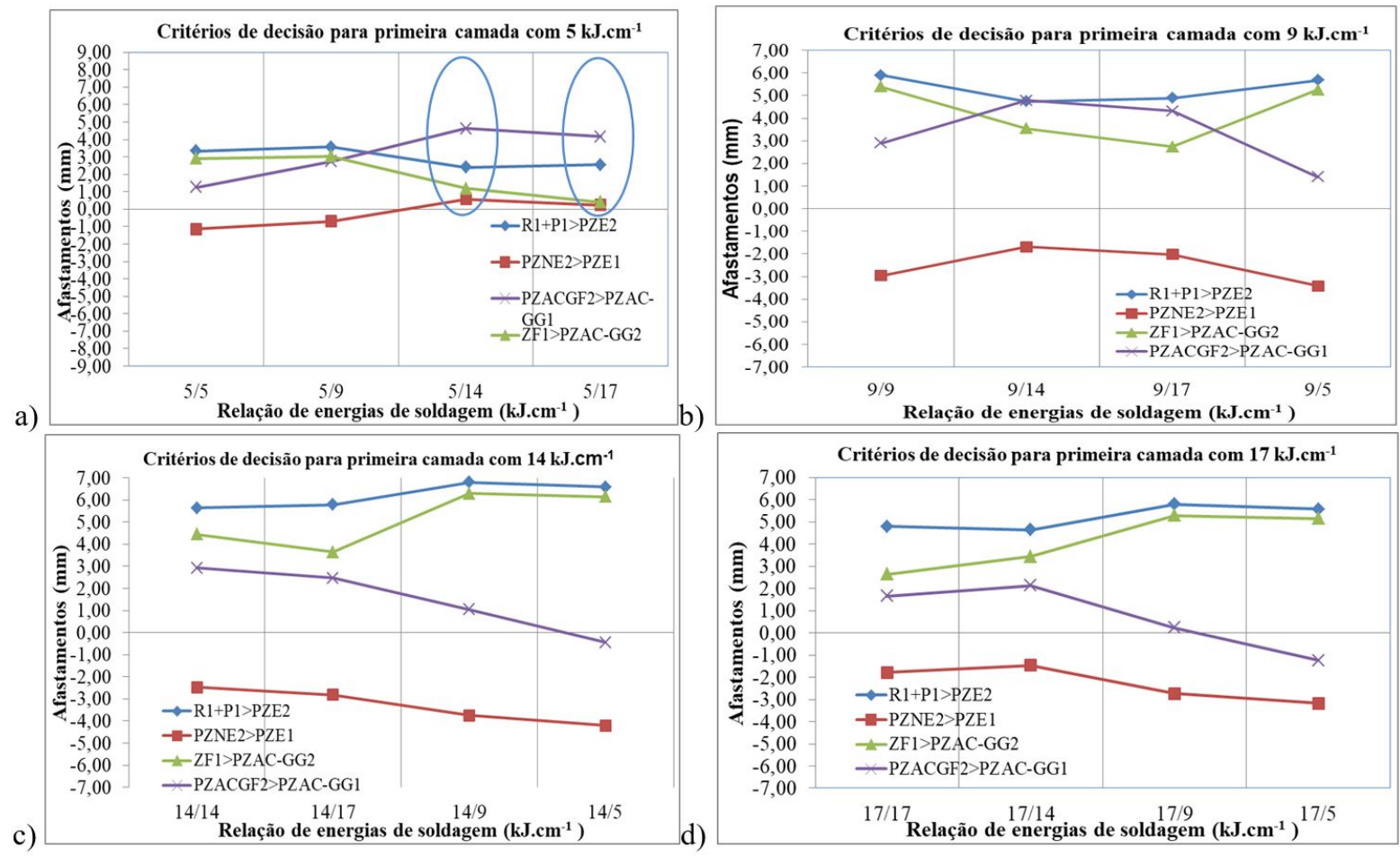

b)

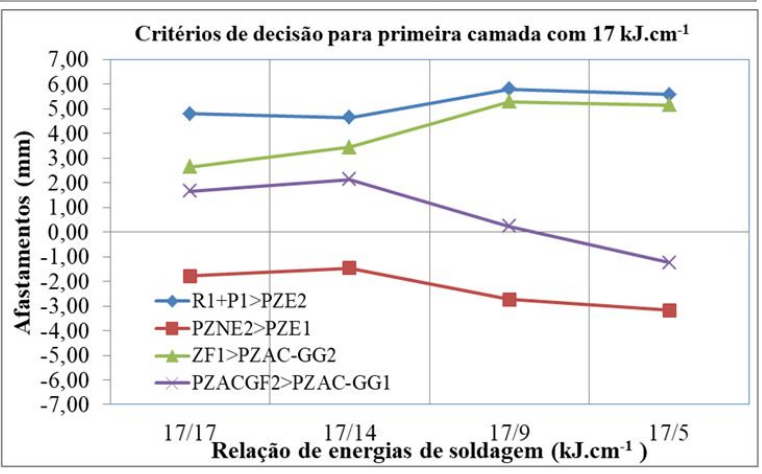

Figura 7. Diagrama de decisão para a energia de: a) $5 \mathrm{~kJ} \cdot \mathrm{cm}^{-1}$, b) $9 \mathrm{~kJ} . \mathrm{cm}^{-1}$, c) $14 \mathrm{~kJ} . \mathrm{cm}^{-1}$ e d) $17 \mathrm{~kJ} . \mathrm{cm}^{-1}$.

\section{- Relação E1/E2 com $5 \mathrm{~kJ} . \mathrm{cm}^{-1}$ na primeira camada}

A Figura 7 (a) apresenta os afastamentos para as relações com a primeira camada soldada com uma energia de $5 \mathrm{~kJ} . \mathrm{cm}^{-1}$ e a segunda camada com $5 \mathrm{~kJ} . \mathrm{cm}^{-1}, 9 \mathrm{~kJ} . \mathrm{cm}^{-1}, 14 \mathrm{~kJ} . \mathrm{cm}^{-1}$ e $17 \mathrm{~kJ}_{\mathrm{cm}}$. . Observa-se que, as combinações de energia $5 / 14$ e $5 / 17$ $\mathrm{kJ} . \mathrm{cm}^{-1}$ apresentam afastamentos positivos para todos os critérios. Como mais de uma relação de energias foi aprovada utilizou-se o mesmo critério de Cruz [10], que delimita o critério estabelecido na Equação $1\left(P Z N E_{2}\right)>\left(P Z E_{1}\right)$, como

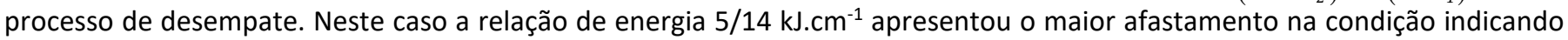
uma maior capacidade da ZNE da segunda camada poder revenir a ZE da primeira camada.

\section{- Relação E1/E2 com 9, 14 e 17 kJ.cm ${ }^{-1}$ na primeira camada}

As Figuras 7 (b), (c) e (d) apresentam os afastamentos para as relações com a primeira camada soldada com energia de 9 , 14 e $17 \mathrm{~kJ}_{\mathrm{cm}} \mathrm{cm}^{-1}$ e a segunda camada com 5, 9, 14 e $17 \mathrm{~kJ} . \mathrm{cm}^{-1}$. Os diagramas mostram que a esta energia imposta na primeira camada apresenta afastamentos negativos para todas as relações de energia para o critério estabelecido na Equação 1 $\left(\left(P Z N E_{2}\right)>\left(P Z E_{1}\right)\right)$ significando que pode não haver um revenimento satisfatório das zonas endurecidas. Somando-se a isto ocorre a rejeição pelo critério da macrografia conforme a Equação $3\left(\left(P Z A C-G F_{2}\right)>\left(P Z A C-G G_{1}\right)\right)$ para as relações de energia de $14 / 5 \mathrm{~kJ} . \mathrm{cm}^{-1}$ e $17 / 5 \mathrm{~kJ} . \mathrm{cm}^{-1}$.

Deve-se observar que energias muito elevadas na primeira camada e muito baixas na segunda, proporcionam uma ZACGG muito extensa e com um crescimento de grão excessivo na primeira camada, o que poderá reduzir a tenacidade desta região, pois o aquecimento proporcionado pela energia da segunda camada pode não ser suficiente para causar o grau de refino desejado $[4,14,15]$.

Outro fator importante é que, quando a energia usada na segunda camada é baixa, as variações de temperatura causadas por essa não são suficientes para o refinamento da ZAC-GG e revenimento da região endurecida da primeira camada. A medida que são utilizados parâmetros com maior energia para segunda camada, esse problema é reduzido a partir de valores de afastamento maiores [7].

Com este resultado estas relações de energias estão descartadas para aplicação na técnica da dupla camada.

Conforme pode ser observado tem-se uma menor chance na aprovação dos critérios quando se aumenta o aporte térmico da primeira camada. Alguns estudos $[4,6,10]$ já apontavam em suas conclusões a dificuldade em revenir e refinar a região de crescimento de grão da primeira camada em virtude do aumento das medidas de penetração das zonas endurecidas.

Os resultados avaliados pelos diagramas de decisão mostram que para as condições avaliadas neste trabalho a relação de energia que se mostrou mais adequada foi a relação $5 / 14 \mathrm{~kJ} . \mathrm{cm}^{-1}$. 


\subsection{Soldagem com dupla camada com deposição sobre chapa}

Para comprovar a eficácia da aplicação da relação de aportes térmicos e do método de seleção por diagramas de decisão avaliou-se o revenimento gerado pela técnica de dupla com a relação $5 / 14 \mathrm{~kJ} . \mathrm{cm}^{-1}$.

A Figura 8 apresenta a macrografia da amostra de dupla camada para a relação de energia $5 / 14 \mathrm{~kJ} . \mathrm{cm}^{-1}$ apresentando uma possível região de refino de grão ocasionada pela dupla camada.

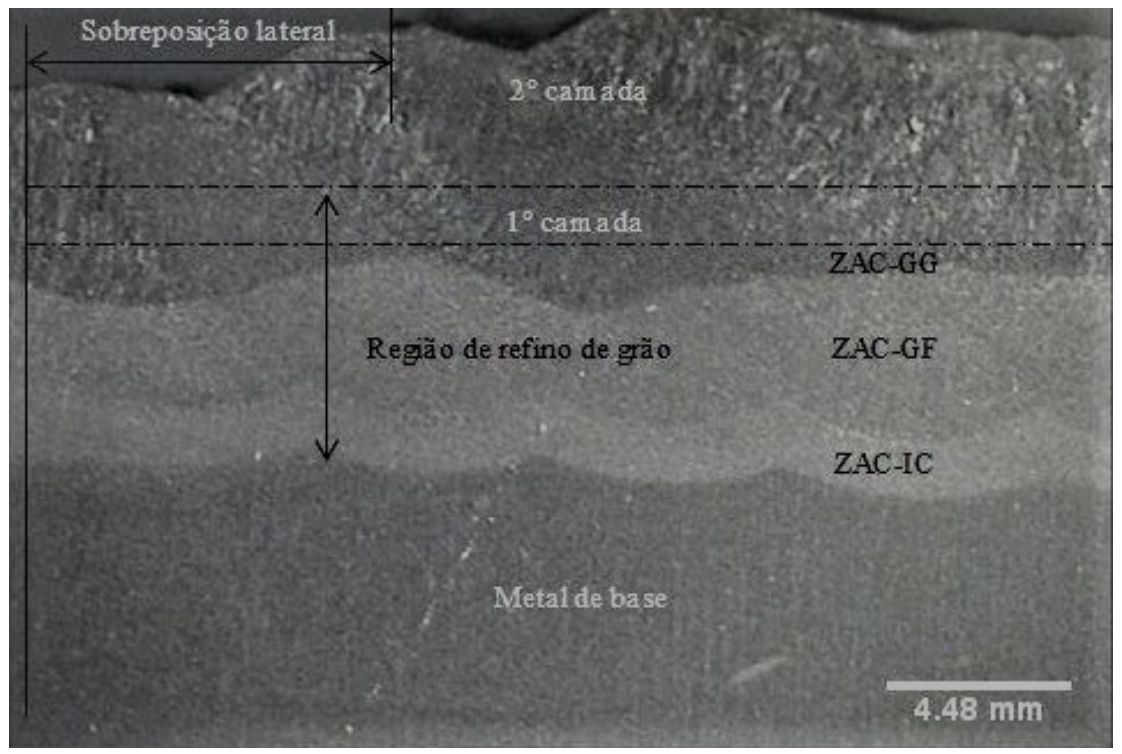

Figura 8. Macrografia do cordão de solda para ensaio em dupla camada para a relação de energia de soldagem $5 / 14 \mathrm{~kJ} . \mathrm{cm}^{-1}$.

A Figura 9 apresenta os perfis de microdureza medidos a partir da linha de fusão (LF) da primeira camada (conforme apresentado na Figura 3) no corpo de prova ensaiado com $5 \mathrm{~kJ} \mathrm{~cm}^{-1}$ na primeira camada e $14 \mathrm{~kJ}^{\mathrm{cm}} \mathrm{cm}^{-1}$ na segunda camada e sua comparação com a soldagem preliminar.

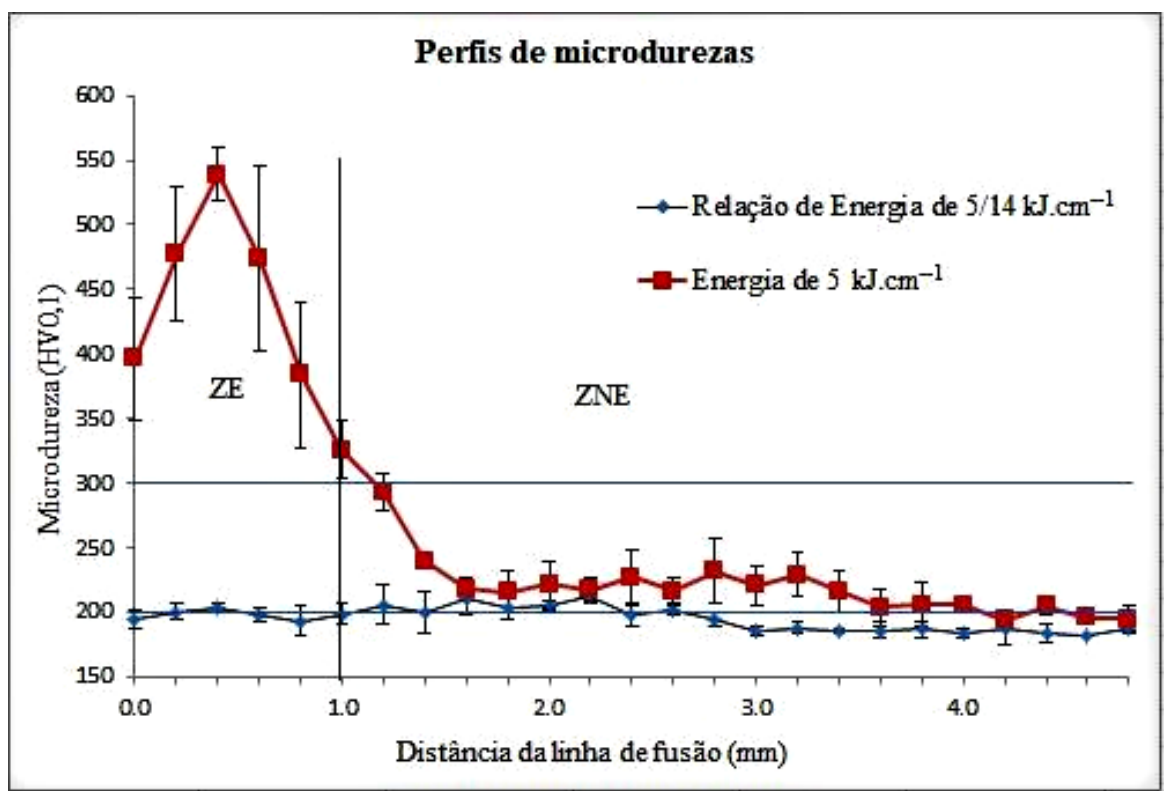

Figura 9. Comparação entre os perfis de microdurezas da dupla camada com a soldagem preliminar.

Observa-se que o perfil de microdureza obtido com a relação de energias $5 / 14 \mathrm{~kJ}_{\mathrm{cm}} \mathrm{cm}^{-1}$ não apresentou valores superiores ao que define a ZE $(300 \mathrm{HVO}, 1)$, demonstrando a possibilidade de revenimento promovido pela dupla camada naquela região. A microdureza ficou na faixa de $200 \mathrm{HV0}, 1$, bem abaixo do limite de $300 \mathrm{HVO}, 1$.

$O$ refinamento e o revenimento observado na ZAC da primeira camada se devem em parte ao passe lateral nesta mesma camada que, com uma sobreposição aproximada de 50\%, alcançou sobre a ZAC-GG do passe anterior a sua ZAC-GF. 
Adicionalmente houve a sobreposição da ZAC-GF da segunda camada sobre a região da ZAC-GG da primeira camada, atendendo aos critérios definidos pela técnica da dupla camada que, por sua vez, diminuíram a possibilidade de uma zona endurecida a partir da formação de martensita endurecida não revenida na região [10].

Os resultados ficaram dentro do esperado e confirmam a relação de energia escolhida como adequada para a técnica da dupla camada. Vários autores $[4,10,11]$ encontraram, em seus respectivos trabalhos, resultados semelhantes para esta técnica.

\section{Conclusões}

Baseado nos resultados experimentais obtidos nos ensaios realizados no aço ASTM A 131 Grau AH36 com espessura de $12,5 \mathrm{~mm}$ soldado pelo processo GMAW com intuito de escolher a relação de energia apropriada pode-se relacionar os seguintes conclusões:

- A dimensão do reforço aumentou quando se variou a energia de 5 para $9 \mathrm{~kJ}_{\mathrm{cm}} \mathrm{cm}^{-1}$, e para os demais aumentos do aporte térmico não se observou uma variação significativa na dimensão do reforço. Já os valores de penetração não obtiveram variação significativa para as energias de 5 e $9 \mathrm{~kJ}_{\mathrm{cm}}{ }^{-1}$, porém observou-se um aumento da medida da penetração da energia de 9 para a de $14 \mathrm{~kJ} . \mathrm{cm}^{-1}$, que provavelmente ocorreu devido ao aumento do aporte térmico utilizado;

- Para todas as condições de energia de soldagem estudadas observou-se a formação de uma região endurecida ao se depositar apenas um cordão de solda, sendo que o valor de microdureza máxima e comprimento da região endurecida diminuíram com o aumento da energia de soldagem;

- Os resultados indicaram que a relação de energias de soldagem com 5/5, 5/9, 5/14 e 5/17 kJ.cm-1 foram aprovadas

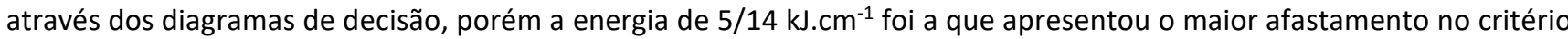
do perfil do cordão baseado na microdureza;

- A soldagem com dupla camada sobre chapa plana apresentou perfil de microdureza valores inferiores ao que define a ZE (300 HV0,1), demonstrando a possibilidade de revenimento ocasionado pela sobreposição dos passes promovido pela dupla camada naquela região. Os resultados ficaram dentro do esperado e confirmam a relação de energia escolhida como adequada para a respectiva técnica.

\section{Agradecimentos}

Os autores deste trabalho agradecem ao PPMec da Escola de Engenharia da Universidade Federal do Rio Grande e a CAPES/FAPERGS pelo suporte financeiro.

\section{Referências}

[1] Meester B. The weldability of modern structural TMCP steels. ISIJ International, Japan. 1997;37(6):537-551. http://dx.doi.org/10.2355/isijinternational.37.537.

[2] Ribeiro ACN, Henein H, Ivey DG, Brandi SD. Evaluation of AH36 microalloyed steel welded joint by submerged arc welding process with one and two wires. Materials Research, São Paulo. 2016;19(1):143-152. http://dx.doi.org/10.1590/1980-5373-MR-2015-0532.

[3] Niño CEB. Especificação de procedimentos de reparo por soldagem sem tratamento térmico posterior - efeito do revenimento produzido pelos ciclos térmicos [tese de doutorado]. Florianópolis: Universidade Federal de Santa Catarina; 2001.

[4] Farias JP, Aguiar WM. Soldagem do aço ABNT 4140 sem tratamento térmico posterior. Revista Tecnologia, Fortaleza. 2003;24(1):26-36.

[5] Lant T, Robinson DL, Spafford B, Storesund J. Review of weld repair procedures for alloy steels designed to minimise the risk of future cracking. International Journal of Pressure Vessels and Piping, USA. 2001;78(11-12):813-818. http://dx.doi.org/10.1016/S03080161(01)00094-1.

[6] Oliveira GL. Soldagem dissimilar dos aços AISI 8630M e ASTM A182 F22 para aplicações subaquáticas [tese de doutorado]. Fortaleza: Universidade Federal do Ceará; 2013.

[7] Brito FFG. Avaliação da técnica da dupla camada na soldagem TIG considerando a tenacidade e características metalúrgicas de juntas de aço AISI 8630M e ASTM A182 F22 [dissertação de mestrado]. Fortaleza: Universidade Federal do Ceará; 2014.

[8] Andrade TC. Desenvolvimento e análise de técnicas de soldagem de reparos com deposição em dupla camada de aços inoxidáveis AWS ER309L e AWS ER347 aplicados sobre aços estruturais 2,25Cr-1Mo e 2,25Cr-1Mo-025V [dissertação de mestrado]. Fortaleza: Universidade Federal do Ceará; 2016.

[9] Cavalcante NE, Andrade TC, Pinheiro PHM, Miranda HC, Motta MF, Aguiar WM. Estudo de procedimentos de soldagem MIG/MAG para aplicação de revestimento de liga de níquel inconel 625 em aço estrutural ASTM A387 gr.11. Revista Soldagem \& Inspeção, Brasil. 2016;21(1):70-82. http://dx.doi.org/10.1590/0104-9224/SI2101.07. 
[10]Cruz RLS. Avaliação dos efeitos da técnica da dupla camada na soldagem do aço ASTM A 516 grau 60 [dissertação de mestrado]. Fortaleza: Universidade Federal do Ceará; 2006.

[11]Azevedo AGL. Aplicação da técnica da dupla camada na soldagem do aço ABNT 1045 [dissertação de mestrado]. Fortaleza: Universidade Federal do Ceará; 2002.

[12] Hu J, Du LX, Wang JJ, Gao CR. Effect of welding heat input on microstructures and toughness in simulated CGHAZ of V-N high strength steel. Materials Science and Engineering A. 2013;577:161-168. http://dx.doi.org/10.1016/j.msea.2013.04.044.

[13] Machado IG. Soldagem \& técnicas conexas: processos. Porto Alegre: Laboratório de Soldagem \& Técnicas Conexas; Centro de Tecnologia; Universidade Federal do Rio Grande do Sul; 1996.

[14] Niño CEB, Buschinelli AJA. Análise de alternativas de reparo por soldagem de aços Cr-Mo. In: Anais do XXI Encontro Nacional de Tecnologia da Soldagem; 1995 Junho; Caxias do Sul, Brasil. Caxias do Sul: ENTS; 1995. p. 241-257.

[15] Arraes RM Jr. Avaliação da Tenacidade da ZAC na Soldagem do Aço ABNT 4340 sem Tratamento Térmico Posterior [dissertação de mestrado]. Fortaleza: Universidade Federal do Ceará; 2001. 